\title{
Nuevas aportaciones a la conservación y restauración decimonónica en la Catedral de Sevilla
}

\author{
Ana Galán Pérez
}

Resumen: El presente artículo ofrece nuevas aportaciones a la conservación y restauración decimonónica en la Catedral de Sevilla, reconociendo una diversidad en el origen del corpus normativo y legal de protección de la Catedral, identificando las metodologías en su consecución así como las prioridades en las intervenciones restauradoras, comprobando a su vez la formación de las relaciones institucionales que han generado una red en torno al cabildo, con especial relevancia a los profesionales que se dedicaron a la conservación y restauración.

Palabras clave: Conservación, restauración, historia, Catedral de Sevilla, archivo, gestión patrimonio cultural, siglo XIX.

\section{Novos contributos para a conservação e restauro do século XIX na catedral de Sevilha}

Resumo: O presente artigo oferece novos contributos para a conservação e restauro do século XIX na catedral de Sevilha, reconhecendo uma diversidade na origem do corpus normativo e legal de protecção à catedral. Também foram identificadas as metodologias da sua execução, assim como as prioridades nas intervenções de conservação, comprovando as relações institucionais que criaram uma rede à volta do cabido, com especial relevância aos profissionais que se dedicaram à conservação e restauro.

Palavras-chave: Conservação; restauro; história; catedral e Sevilha; arquivo; gestão; património cultural; século XIX.

\section{Contributions to the nineteenth century conservation and restoration of the Cathedral of Seville}

Abstract: This article offers new contributions about Conservation and Restoration at the Cathedral of Seville, recognizing diversity in the origin of the normative and legal corpus for the protection of the Cathedral, identifying the methodologies to their achievement as well as priorities in the restoration interventions, checking at the same time the formation of institutional relationships that have generated a network around the cabildo, with special relevance to practitioners who were dedicated to the preservation and restoration.

Key words: Conservation, Restoration, History, Seville Cathedral, Archive, Cultural Heritage Management, 19 th Century.

\section{Corpus normativo de protección: Reales Órdenes, comisiones internas y criterios internos y externos}

Una de las primeras normas del siglo XIX que llega a la Catedral de Sevilla es la Real Cédula de 1803: Real Cédula por la que se aprueba y manda observar la Instrucción formada por la Real Academia de la Historia sobre el modo de recoger y conservar los Monumentos Antiguos?. Dicha Cédula es la normativa que se genera debido a la constatación de la pérdida o robo del patrimonio como las ruinas de Itálica, además de la intención de restaurarlos y conservarlos en el mejor estado posible. Este término "recoger" nos acerca a un procedimiento de inventario y catalogación por el que el 
Real Decreto se constituye por su precisión y profundidad, un primer intento catalográfico tal y como señala González-Varas (1999: 173-183). El cabildo catedralicio es agente responsable, necesario ejecutor de dicha norma y por ello responsable de la conservación de la colección catedralicia, pues se establece "la obligatoriedad de que dichas normas se lleven a cabo por parte de M.RR. Arzobispos, RR. Obispos y demás Prelados con jurisdicción vere nullius, al igual que Alcaldes, Chancillerías y Audiencias Reales, Corregidores, Asistente, Intendentes, Gobernadores y Alcaldes Mayores del Reino." Norma, por otra parte, de obligado cumplimiento desde la monarquía vigente ante las pérdidas, robos y otros actos vandálicos reconocidos hacia los objetos artísticos. Subraya, además, la necesidad de una institución como la Real Academia de la Historia, especializando la tarea de preservación de Monumentos y Arqueología, concretamente, la protección de objetos concernientes a la historia, las "cosas antiguas", frente a la otra línea de protección como son los objetos artísticos tutelados por los recién inaugurados Museos de Bellas Artes (de ámbito provincial en su mayoría), Galerías, Pinacotecas y las Academias de Bellas Artes. Es decir, a lo largo del siglo XIX comprobamos la "consideración de dos valores posibles: el histórico y el artístico" (Bolaños 1997:208). Por ello es interesante destacar que se vislumbran ya los antecedentes del concepto de patrimonio cultural, puesto que se hace un llamamiento a preservar lo que se considera propio de todo el estado Español. Carlos IV inaugura con este documento un modelo a seguir que permanecerá vigente todo el siglo XIX.

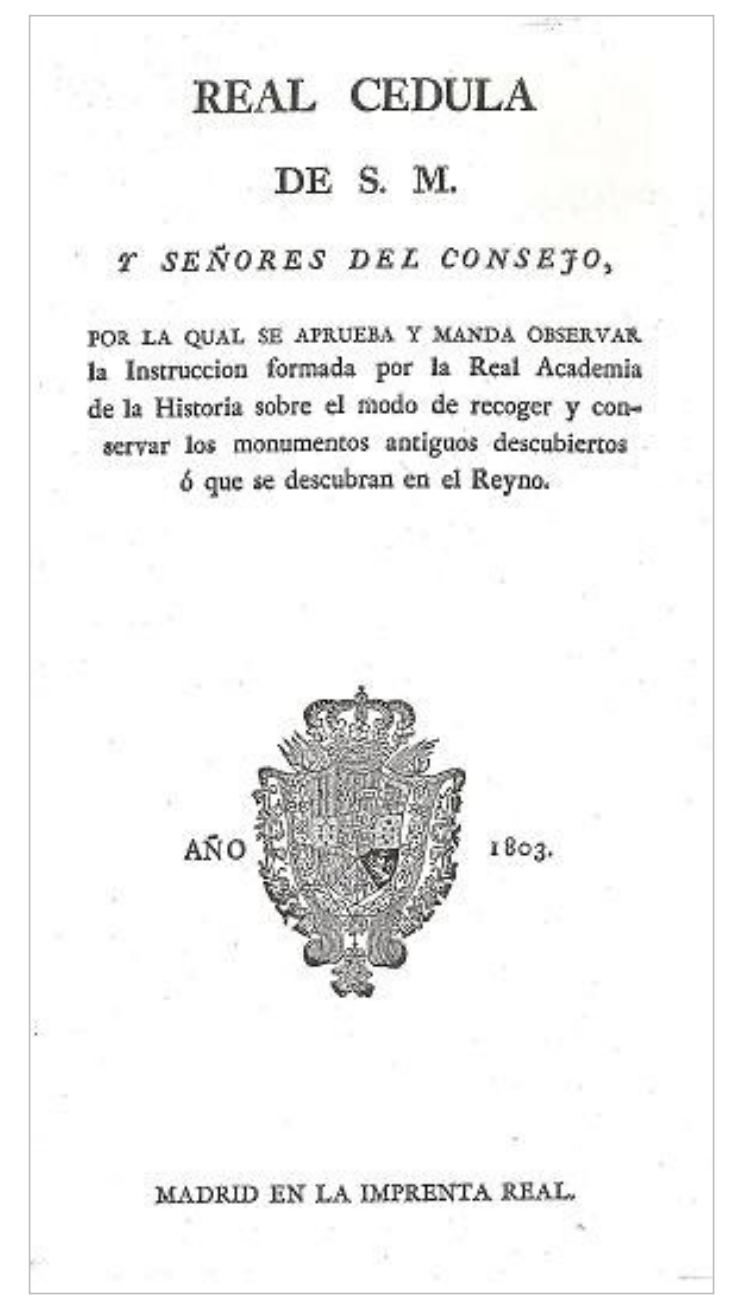

Figura 1. Portada inicial de la Real Cédula de 1803. A.C.S. 
En el año 1826, llega al cabildo catedralicio otra Real Orden y en este caso atiende a la base moral sobre la que se apoya la normativa de protección: Real Orden por la que se nombran revisores por las jurisdicciones Eclesiástica y Civil para evitar la circulación de libros impíos, estampas y pinturas obscenas ${ }^{2}$. Así, sabemos que se estableció una "regla" respecto a criterios éticos y religiosos, existiendo una colaboración patente entre entidades civiles y eclesiásticas, nombrándose una serie de inspectores por las jurisdicciones Eclesiástica y Civil que comprobaban una "normalidad" en cuanto al movimiento e intercambio de libros e imágenes. Así, movimiento y accesibilidad de las obras artísticas como son las estampas y pinturas, son susceptibles de control en la medida en que sus contenidos e iconografía no responden al decoro y la moralidad de ese momento.

Del año 1881, y finalizando la serie de normas de obligado cumplimiento que proceden de la monarquía, la Real Orden transmitida al Deán de la Catedral a través del Director General de Fomento, entidad que traslada la intención de la Restauración de la Catedral por un arquitecto determinado por el mismo monarca: Traslado de una comunicación del Director General de Fomento en la que se comunica la orden del Rey de restauración de la Catedral de Sevilla dirigida por el arquitecto Adolfo Fernández de Casanova ${ }^{3}$. La Catedral de Sevilla se considera monumento artístico, además de templo religioso, en la que su conservación y restauración es responsabilidad de la monarquía, así como la determinación del director de la restauración, esto es, del arquitecto que va a acometer las obras, que en este caso es Adolfo Fernández de Casanova, definiendo y estructurando el perfil de arquitecto que se dedica a la intervención a nivel estructural de la Catedral, siendo así un agente significativo en su protección.

A continuación, destacamos el conjunto de criterios y teorías de conservación y restauración seguidas en la Catedral, pues aportan información sobre las pautas de actuación del cabildo y estructuran un hilo conductor. Comenzaremos atendiendo a los criterios de origen interno: los acuerdos y concordatos, siendo el primero registrado el del año 1861, Concordato entre la Santa Sede y el Gobierno de España. En Documentos sobre la ejecución de concordato entre la Santa Sede y el Gobierno de España en lo relativo a los bienes eclesiásticos pertenecientes al Arzobispado y a la Catedral de Sevilla $a^{4}$ conocemos la gestión o aquellas cuestiones que tienen en consideración los bienes eclesiásticos, entre los que se encuentran los bienes litúrgicos, bajo un criterio de colaboración y atribución de responsabilidades interinstitucional. Años más tarde, en 1882: Arzobispado de Sevilla notifica que se tomen las medidas oportunas para conservar objetos debido al comienzo de obras ${ }^{5}$, se emite una carta en la que se notifica lo siguiente:

"Habiéndose acordado por la Junta creada por el Gobierno de S.M, y para dirigir las obras que se han de practicar en nuestro templo Metropolitano, que se de comienzo a los trabajos en el día 25 del actual, lo participo a ud. con el fin de que pueda adoptar las medidas que estime oportunas así para la conservación de los objetos que existan en esa zona del templo que debe ocupar la obra, como en la manera de ordenar los oficios y celebración de culto."

De esta manera, se informa y orienta al cabildo para que organice la manipulación las obras siguiendo unas pautas de conservación, y así como su nueva ubicación, puesto que no es aconsejable que permanezcan cuando estén las obras. El consejo y notificación de este movimiento, camina junto a la atención y consideración hacia los feligreses que acuden al templo para escuchar la liturgia, puesto que debe adaptar el culto a la nueva situación, tanto por su colección como por aquellos que son el objeto y sentido de generar dicha colección. Dicha recomendación se repite en el mismo año, Salida de correspondencia del Sr. Arzobispo D. Joaquín Lluch y Garriga al Cabildo: inicio de la obra de la Catedral, organización de celebración de culto y 
conservación de los objetos situados en la zona de la obra ${ }^{6}$. Es decir, se está identificando las posibles causas de deterioro en la gestión de los espacios y los objetos para su correcta conservación.

Los criterios conservadores decimonónicos procedentes del propio cabildo catedralicio se recogen también gracias a las comisiones internas. Dichos grupos de personas se constituían para atender asuntos puntuales y el objeto de tal formación era la consecución del éxito de la empresa encomendada. Esta fórmula sugiere lo que consideramos en la actualidad el trabajo transversal, y subraya la consideración de la formación de una red institucional en torno a la colección catedralicia. Pero además, se nos ofrece la perspectiva de una organización interna del cabildo, y constatamos cómo son los individuos que lo componen, los que aportan sus ideas, tendencias y consideraciones. Así, sabemos que en el siglo XIX, dentro del propio cabildo de la Catedral de Sevilla existe una tendencia ilustrada y una tendencia conservadora, tal y como comprobamos en la intención de restauración y los criterios a seguir en el caso de la pintura mural de la Virgen de la Antigua, triunfando finalmente la tendencia ilustrada que apoyaba la intervención de conservación. Este caso del año 1777 sienta los precedentes en cuanto a la generación de comisiones internas como una pauta de trabajo, en este caso formada por el presidente de la capilla de la Antigua y por el Mayordomo de Fábrica y que se establecían tras una alerta en cuanto al estado de conservación de la Virgen de la Antigua (Serrera 1990:171-177), acontecimiento que tuvo su reflejo también en el siglo XIX y por ello resulta imprescindible nombrar a José Escacena y Diéguez, restaurador de la Virgen de la Antigua, quien llevó a cabo la intervención después de que el cabildo desestimara el ofrecimiento del pintor y restaurador Juan Oliva. El cabildo otorgó a José Escacena el título de "Restaurador de los cuadros de la Catedral"7, que antes había desempeñado Manuel Lucena (Serrera, 1987). Finalmente, y tras lo que podemos considerar precedentes del siglo XIX, en 1875 comprobamos la creación de comisiones de trabajo para tratar aspectos relacionados con la colección catedralicia a través de la Carpeta de la Comisión de Restauración de Murillo 8 .

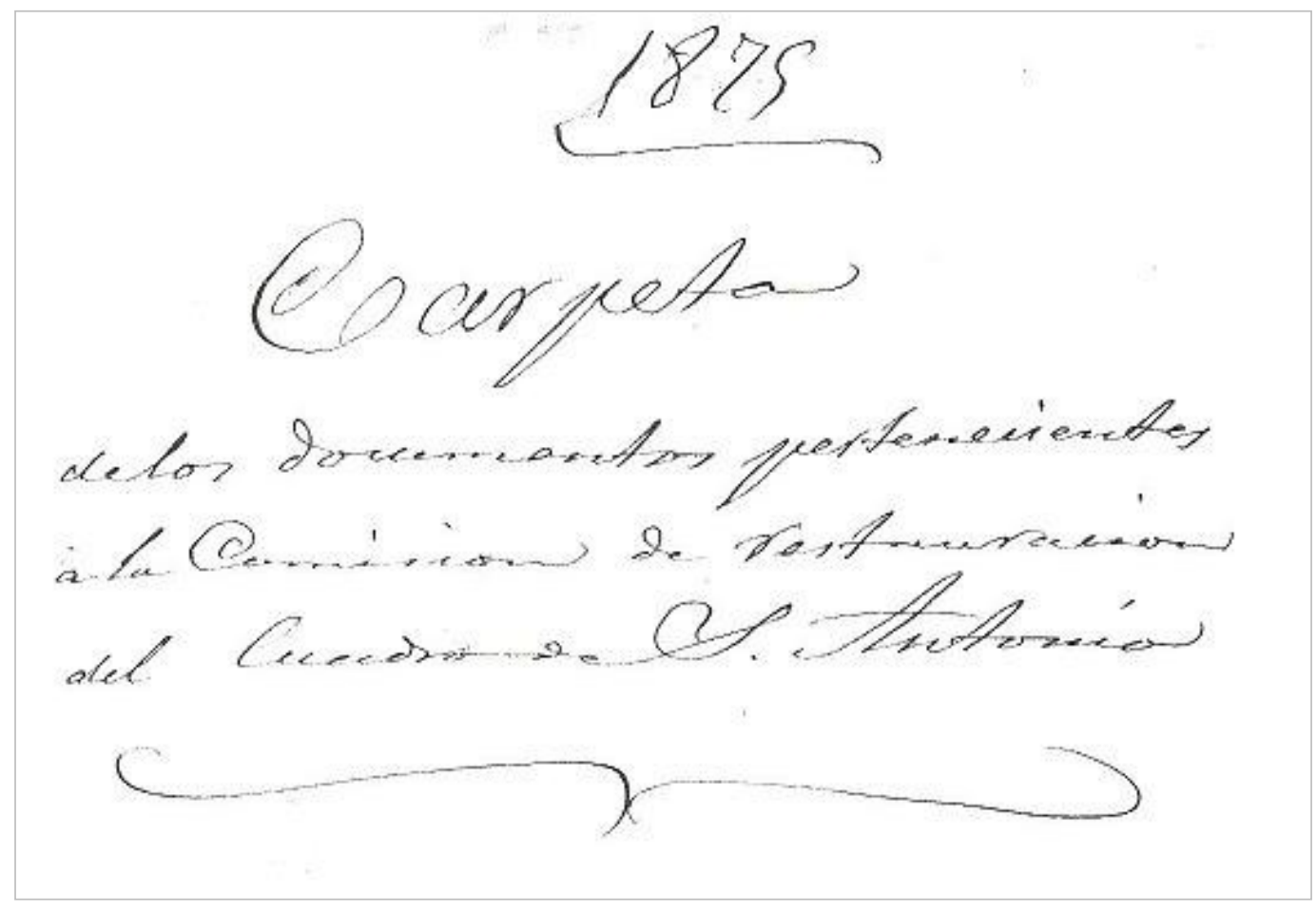

Figura 2. Primera página de la Carpeta de la Comisión de Restauración. A.C.S. 
En todo este corpus normativo de conservación, cabe destacar el peso que han tenido los criterios procedentes de agentes externos íntimamente relacionados con las decisiones del cabildo respecto a su colección, es decir, instituciones locales y estatales con autoridad en materia de objetos muebles constitutivos de colecciones, su conservación y difusión. Una fecha significativa es el año 1881, por el cual la Comisión de Monumentos históricos y Artístico de Sevilla se pronuncia sobre las actuaciones futuras en la Catedral ${ }^{9}$. La orden de la Dirección General de Instrucción Pública que llega a la Comisión de Monumentos a través del Gobernador Civil de la Provincia. Comisión de Monumentos históricos y Artísticos de la provincia de Sevilla, sobre las obras de la Catedral ${ }^{10}$. Así, se informa al Deán y se le solicita respuesta con el fin de reunirse para informar a esta comisión:

“(...) y teniendo en cuenta que es uno de los monumentos más preciados de la nación, solicita a la Comisión de Monumentos que realice un seguimiento para asegurarse que se cumple la normativa y la reglamentación vigente de las Comisiones." "(...) Le recuerda la potestad que tienen las Comisiones de Monumentos, de detener las obras que adulteren el carácter histórico y artístico de los edificios públicos."

Las Comisiones de Monumentos marcarán la pauta conservadora, como también de los criterios de restauración arquitectónica imperante a finales del siglo XIX, y que influirán en la propia restauración de la Catedral comenzada por Adolfo Fernández Casanova en 1881, seguidor del arquitecto Juan de Madrazo y Küntz, y éste a su vez del francés Viollet Le Duc, arquitecto restaurador de Nôtre Dame de París. Precisamente, es este último quien establece las doctrinas de la "restauración en estilo" en el siglo XIX (Morales, 1996). Surge en este momento de tendencia en estilo, la Comisión de Monumentos Históricos y Artísticos de Sevilla y por ello defiende que "no se adulteren el carácter histórico y artístico de los edificios públicos". Sobre las personas que forman parte de la Comisión, en el presente expediente comunica que siguiendo el artículo 21 de la Regla $3^{a}$ del Reglamento de las Comisiones Provinciales de Monumentos, "se nombra a D. Leoncio Baglietto y D. Ángel Ayala, para que practiquen el reconocimiento facultativo y arqueológico de la portada que va terminarse y restaurarse." Solicita, además, a modo de programación que determine el día y hora para que tales personas puedan llevar a cabo la inspección y se subraya la obligatoriedad que "bajo ningún concepto dejen de cumplirse las disposiciones", siendo de información urgente si se ha tenido en cuenta el Reglamento, para requerir notificación al respecto.

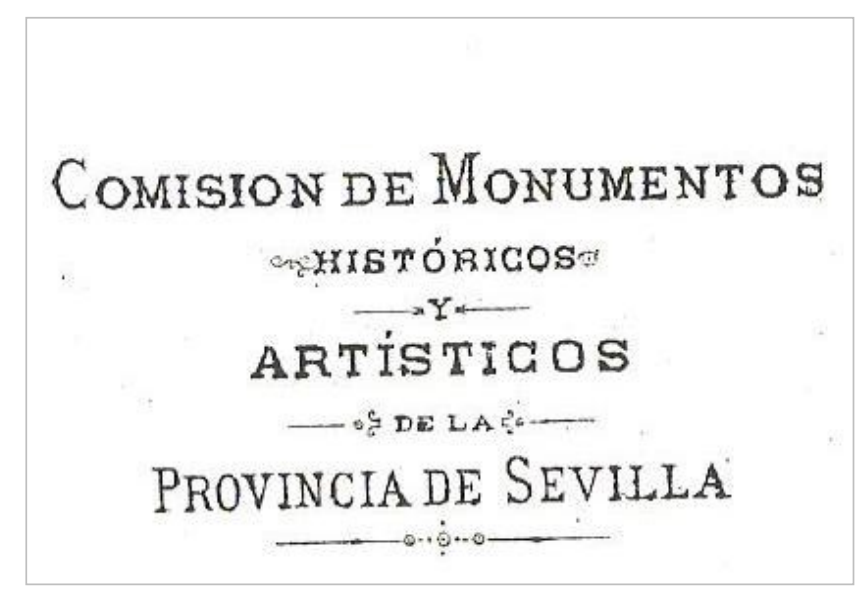

Figura 3. Membrete de correspondencia de la Comisión de Monumentos Históricos y artísticos de la provincia de Sevilla, 1898. A.C.S. 


\section{Conservación preventiva e intervención restauradora en la Catedral}

A finales del siglo XIX, la rehabilitación de la estructura de la Catedral de Sevilla queda patente en los informes, proyectos y memorias, aludiendo tanto a los procedimientos, como a los costes económicos y los recursos humanos. Así, continente vinculado con el contenido, Catedral y colección, forman una sola unidad, resultando clave distinguir y agrupar aquellos elementos de deterioro del patrimonio artístico mueble, entre los que camina intrínseco el devenir del propio edificio y sus restauraciones, así como los medios de control ideados por el Cabildo. Asimismo, en las intervenciones en la colección catedralicia distinguimos dos tipos de actuaciones: las relacionadas con la conservación preventiva, tras las cuales está mucho más presente el Cabildo y los agentes sociales; y las actuaciones restauradoras heterogéneas, pues se aplican según la tipología y naturaleza de los bienes muebles, por su finalidad y la categoría otorgada.

En dichas actuaciones conservadoras son fundamentales las iniciativas de cooperación y relación institucional, verdadero punto de inflexión e inicio en los precedentes hacia la gestión del patrimonio cultural, estudiando las sinergias y las actuaciones de calidad y sostenibilidad entre los distintos agentes que a lo largo del siglo XIX consideraron propia a la Catedral, otorgándole de esta manera su consideración patrimonial (Galán 2012: 315-322).

De 1881 a 1900 se lleva a cabo una restauración integral y sistemática a nivel estructural en la Catedral de Sevilla, realizada por el arquitecto Adolfo Fernández Casanova (González-Varas 1994: 242) que tuvo su motivo en la caída y destrucción del cimborrio por el que se perdieron además las bóvedas adyacentes. Sabemos que provocaron múltiples daños en el órgano, y podemos imaginar la nube de polvo que se generaría sobre los bienes muebles con la consecuente degradación. Así, en 1883, el arquitecto se pronuncia e informa con: "la Dirección facultativa de las obras de Restauración de la Catedral comunica la finalización de la obra en el tramo del $\operatorname{coro}^{11}$ y en 1884 , de la misma mano se emite un informe: Dirección de las obras de Restauración de la Catedral' ${ }^{12}$. En este notifica las actuaciones realizadas y se refiere a las medidas de seguridad y prevención en los siguientes términos:
"Terminados ya los apeos y encimbrados relativos al pilar ruinoso del trazo sur del crucero de nuestra grandiosa Catedral, continuará con el corte del este apoyo. Ud. comprenderá perfectamente cuán arriesgadísimos son los trabajos necesarios para dejar colgadas cuatro bóvedas que a más de hallarse ya tan resentidas, pertenecen al más gigantesco Templo de la Edad Media en Europa. Estas circunstancias me obligan a rogar a ud. se digne disponer la suspensión temporal del culto en la región central y en la banda sur de nuestra Basílica y únicamente podrán utilizarse las Capillas de la cabecera y del costado norte, en el caso de no ocurrir complicaciones en los trabajos de desmonte del repetido pilar. Sevilla, 25 de noviembre de 1887".

Finalmente, destacamos la renuncia del propio arquitecto director de las obras de restauración, comprobando que el protocolo de relaciones institucionales de tal perfil de ArquitectoRestaurador con el de la entidad contratante es de tal calibre, que queda recogido en expedientes como el del año 1888: Traslado de una comunicación del Ministro de Fomento en la que se dice aceptar la renuncia del Arquitecto de la Catedral Adolfo Fernández Casanova ${ }^{13}$. 


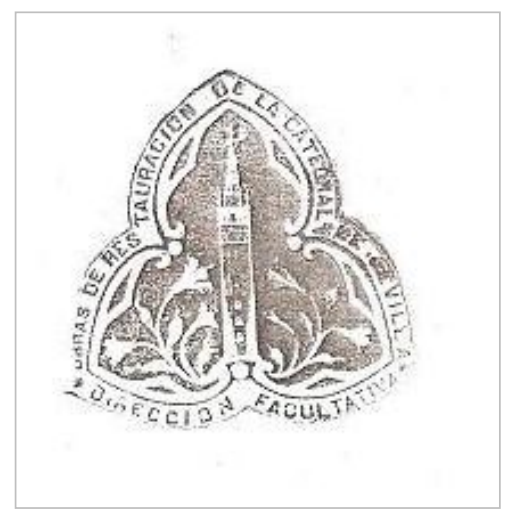

Figura 4. Sello de la Carta emitida por el Arquitecto Adolfo Fernández de Casanova al Cabildo de la Catedral en 1884, respecto a los informes de Conservación de la fábrica del Templo.

Resulta significativo cómo un año anterior al derrumbe, en 1880, se solicitó un informe del estado de conservación ${ }^{14}$, a dos arquitectos que posteriormente no intervinieron en la obra: Informe elaborado por D. Manuel Portillo y D. Juan Talavera, arquitectos, sobre las obras de reparación de la Catedra ${ }^{15}$. Se trata de una inspección sobre el estado de conservación estructural de la Catedral de Sevilla, identificando causas de degradación, y es sumamente interesante cómo los arquitectos lo exponen.

En una primera presentación del informe, aluden a la belleza e importancia que la Catedral tiene a nivel internacional. El "mundo entero" está interesado en su conservación: "nuestra patria no puede cometer que por abandono se deteriore una de las joyas más valiosas de la España Monumental y Artística".

Señalado el significado y relevancia de la Catedral como entidad patrimonial supraestatal, el informe reconoce dos tipos de intervenciones, las reparaciones ordinarias, y obras accidentales a través de las cuales se especifican las causas de deterioro. Estas son, por una parte constructivas esto es, reconocimiento de mala piedra, por otra las antropogénicas derivadas de las malas reparaciones, y finalmente las climáticas que se traducen en vegetación por exceso de agua. Dice así:

"Dentro de las reparaciones ordinarias está la revisión en los tejados de las algas y plantas parasitarias que crecen por la humedad. Provocan filtraciones y deterioro. Para evitarlo, debe haber una cuadrilla de operarios que eliminen los vegetales y apliquen lechadas de cal para evitar la proliferación de plantas. Este trabajo se califica en 10.000 pesetas anuales."[...] "En el segundo género de reparación, se refiere a la seguridad y estabilidad del templo. Varias agujas de terminación de los machones por la oxidación de su alma de hierro, se han abierto en sentido vertical amenazando con desplomarse sorbe las azoteas" [...] "También en las uniones de los arcos torales con las bóvedas hay grietas producidas por asientos que exigen el pronto establecimiento de la tablazón y tanto las ventanas como las cresterías y antepechos han experimentado deterioros." [...] "Lo más grave es la reparación de la bóveda tallada que forma el crucero de la nave de San Pedro, y la del machón que está adosada a la capilla de la Concepción en el Coro. Debido a las filtraciones y a la mala calidad de la piedra, ha necesitado refuerzos en distintas épocas que al colocarse mal son la causa principal de su mal estado. Oxidación del hierro colocado a modo de planchas y grapas". 
Hemos observado que los arquitectos han efectuado lo que hoy denominamos "examen de los bienes culturales" a través de una inspección ocular u organoléptica sobre el estado de conservación. Finalmente, el informe refleja sus particularidades como templo cristiano "sentimiento religioso", pero sobre todo como monumento histórico artístico.

Sigamos con la participación de la sociedad en los procesos de conservación y restauración. El acontecimiento de la destrucción parcial de la Catedral, movilizó a agentes sociales y culturales, la administración pública y entidades políticas, como comprobamos en 1881, Comisión de Monumentos Históricos y Artísticos de la Provincia de Sevilla, sobre las obras de la Catedral ${ }^{16}$. Del año de 1888 resulta interesante por la cantidad de donaciones que se reciben para restaurar el cimborrio de la Catedral, como La Alcaldía de Sevilla ofrece recursos para la reparación de la Catedral ${ }^{17}$, Es la entidad local competente, el Ayuntamiento de la capital bética, el que interviene en primera instancia. Posteriormente recogemos, el Comunicado del Arzobispado de Granada de la creación de una Junta para recabar recursos económicos para la restauración de la Catedral de Sevilla tras la caída de su Cimborrio ${ }^{18}$. Tratándose en este caso, de una entidad eclesiástica.

También en ese mismo año de 1888 se traslada una Carta del Ministerio de Fomento donde se da cuenta del acuerdo tomado en Consejo de Ministros para otorgar ayuda económica a la reparación de la Catedral ${ }^{19}$ y finalmente también en el mismo año, El Gobierno Civil manifiesta el deseo de contribuir a la reparación de la Catedra ${ }^{20}$. Y un año más tarde, 1898 sigue el interés por parte del contexto político, Diputados a Cortes de Estepa, Aracena y Sevilla se dirigen al Deán de la Catedral21, que en aquel momento, era D. Francisco Bermúdez Cañas, para ofrecer su intención y sus recursos económicos para la conservación y restauración de la Catedral. Se trata de un conjunto de tres cartas por las que tres Diputados a Cortes se ofrecen al Cabildo. La primera de ellas, es del Diputado a Cortes por Estepa, en la que responde "al agradecimiento del cabildo por las gestiones realizadas en beneficio de las obras de nuestra Basílica, bajo el cumplimiento de católico y sevillano, amante de las glorias religiosas de este país. Firmado en Sevilla 27/08/1898".

La segunda de ellas es del Diputado a Cortes por Aracena, quien responde a la "atenta comunicación del Cabildo con motivo de las gestiones en los cuerpos colegisladores para obtener a favor de las obras de nuestra hermosa Basílica, la cesión por el Estado del importe del maderamen y demás objetos que sienten en la misma, a terminar la restauración del monumento artístico más hermoso de los templos católicos. Como hijo de Sevilla debe coadyudar a tales deberes. Firmado Luís Palomo, Sevilla 3 de agosto de 1898".

Finalmente, el Diputado a Cortes por Sevilla, ofrece "toda la cooperación que aun cuando modesta es decidida para todo lo relacionado con el hermoso tempo justo y legítimo orgullo de cuantos nacieron en esta ciudad". Nombra una Ley de venta de maderas en beneficio de las obras impulsada especialmente el actual Ministro de Fomento, don Germán Gamazo. Firmado en Sevilla a 6/8/1898. En este contexto de protocolo político, todos han emitido una carta de agradecimiento, con frases afectuosas como indican en las tres situaciones. Los tres afirman que se ven con la responsabilidad de ello, por ser hijos de la ciudad de Sevilla y servir al cabildo.

No sólo es el ámbito político o administrativo el que se preocupa por la conservación de la Catedral. Otros agentes aparecen en escena el mismo año de 1888, como La Real Maestranza de Caballería hace una donación económica para las obras de la Catedral22. Pero mucho más significativo es el expediente por el cual sabemos los vínculos entre instituciones y el sistema de acceso de los museos al público, como es el documento: La Academia de Bellas Artes de Sevilla comunica que su Patronato ha decidido comenzar a cobrar entrada al Museo y destinar ese dinero a las 
obras de reparación de la Catedral por la caída del cimborrio ${ }^{23}$. Comprendemos entonces, que un hecho como la urgencia en la salvaguarda de la Catedral puso en marcha todo un engranaje institucional no sólo político, sino cultural, y por el cual nos constan interesantes documentos, entre ellos los proyectos de rehabilitación arquitectónica, que hoy nos ayudan a hilar la historia de la conservación y restauración en el siglo XIX.

Frente a la protección patrimonial que hemos apuntado en párrafos anteriores, asistimos en el siglo XIX a un cambio de gustos artísticos que deriva en la destrucción de bienes eclesiásticos, y que defendidas en informes de conservación estructural, registran una intención de sustitución no por razones de seguridad, sino simplemente por estética. Así, en el año 1824 el expediente, Restauración de la Capilla del Sagrario ${ }^{24}$, recoge las dos cartas que tratan el examen del arquitecto Silvestre Pérez del templo del Sagrario en la Catedral de Sevilla. Resultan significativas por varios aspectos que analizamos a continuación. El arquitecto Silvestre Pérez comunica en una primera carta, que ya ha realizado las observaciones en el exterior del templo, pero en lo que respecta a su interior dice lo siguiente:

"Por el interior no se ha podido reconocer, porque lo impide la prodigiosa extensión del retablo mayor y sus remates que cubren el arco, no sólo por su paramento, sino también por su arquivolta, elevándose a cubrir gran parte de la media naranja; y si no se hace el benéfico sacrificio de desmantelarlo nunca se reconocerá ni podrá decirse el estado de solidez en el que se halla por esta parte principal. Sevilla, 17 de Marzo de 1824."

En una segunda carta, apunta:

"No puedo dejar de manifestar mi agradecimiento al Ilmo. Cabildo por la deferencia que tuvo a mi indicación (...) mandando que desaparezca del templo un retablo que ha sido ejemplo de las extravagancias del arte, y acordando su reforma (del templo) del modo más regular. Sevilla, 4 de Mayo de 1824".

Comunica, de esta manera, que es necesario desmontar el retablo mayor para saber cómo es el estado de conservación de la estructura arquitectónica de la Catedral. Es decir, estamos siendo testigos de cómo en la propuesta de un arquitecto que está inspeccionando el estado de conservación de la Catedral, sugiere que se desmantele parte de la colección catedralicia que además tiene una función litúrgica. Este retablo, era un retablo barroco de Jerónimo Balbás, y tenemos constancia que tras su destrucción se colocó un templete neoclásico, probablemente del mismo arquitecto Silvestre Pérez, y posteriormente se colocó el retablo de la Hermandad de los Vizcaínos.

En definitiva, se justifica la eliminación del retablo barroco por gusto y estilo, y no por peligro de ruina que fue el motivo por el cual se realizó la inspección de conservación (Serrera 1998:135, citado en Bravo 2010:326). Comprobamos cómo en el siglo XIX las ideas estéticas contribuyen a la conservación y determinan qué elementos son susceptibles de ser eliminados.

Respecto a la conservación y restauración de su colección catedralicia, el Cabildo va a mostrar un espíritu ilustrado. Sus intervenciones siguen y reflejan el desarrollo de la disciplina conservadora y restauradora en el entorno del museo y de las academias, dando lugar incluso a debates interinstitucionales sobre qué academia dispone de los profesionales más adecuados para ejecutar dichas restauraciones, como es el caso en torno a la restauración de La visión de San Antonio de Padua de Murillo, entre la Real Academia de San Fernando y la Real Academia de Santa Isabel de Hungría ${ }^{25}$. La carpeta de la comisión de restauración del cuadro de "La Visión de San Antonio" de 
Murillo, en 1875. Documentos pertenecientes a la Comisión de Restauración del Cuadro de San Antonio de Murillo robado en la Catedral de Sevilla ${ }^{26}$, está formada por veintiuna cartas manuscritas, y le complementa otro grupo de documentos recogidos en el expediente Recuperación de un lienzo de Murillo que había sido robado ${ }^{27}$. La intervención restauradora ha sido ampliamente estudiada (Cortegana 1957; Rallo 1995; Ruiz de Lacanal 1999; Vicente 2010), sin embargo hemos considerado interesante apuntar que a través de la sistematización y protocolos al respecto de los sucesos, así como incluir las instituciones y los nombres propios el Cabildo distingue entre su colección de unas obras respecto a otras, haciéndolas susceptibles de ser conservadas y restauradas.

En esta línea es interesante la contraposición que se genera entre el interés de seleccionar un perfil académico para restaurar un cuadro de Murillo, frente a las intervenciones de conservación y restauración de bienes como el grupo de instrumentos musicales y de medida, que pese a recoger el interés por su salvaguarda, dichas intervenciones las llevan a cabo artesanos que revisan, reparan, y ponen en funcionamiento los mismos, identificando el rasgo determinante: su uso continuado cuya función es constituirse como soporte y ayuda en la misión evangelizadora del templo.

Es la finalidad litúrgica y no otra, por la que este grupo de bienes muebles han sido construidos, pero no por ello se olvida la intención artística en la construcción de cajas esculpidas y elementos ornamentales. De 1884, nos consta el primer expediente: Presupuesto del coste económico de la reparación del Órgano de la Catedral ${ }^{28}$. Observamos cómo el cabildo solicita de manera formal a agentes individuales, profesionales especializados, una estimación económica de lo que supone la restauración. Unos años más tarde, en 1888 , se trata la construcción de un nuevo órgano, en el expediente sobre la: Memoria del Proyecto para la construcción de un Órgano en la Iglesia del Sagrario $^{29}$. Esta recopilación de información en forma de memoria, reconoce la trascendencia que supone disponer de dicho instrumento musical con función litúrgica. Finalmente en 1891, sobre el mantenimiento del Órgano de la Catedral.: Informe de la Comisión encargada de supervisar la terminación y el funcionamiento del Órgano de la Catedraß ${ }^{30}$. Podemos comprobar su peso, puesto que se ha generado una comisión interna de trabajo para hacer un seguimiento de su funcionamiento.

Una vez más asistimos a la generación de comisiones internas en torno a la conservación y restauración de su colección catedralicia, quien solicita la reparación, construcción y puesta a punto de sus órganos y de profesionales que notifican, a su vez, de sus actuaciones.

Respecto a las intervenciones en instrumentos de medida, debemos hacer mención a la reparación y reforma del cuerpo de reloj que Fernández Casanova realiza en 1886, cuando está restaurando la Giralda de la Catedral de Sevilla. Este reloj sabemos que fue encargado por el Cabildo a Fray José Cordero, lego franciscano del Puerto de Santa María. En el proceso de restauración sabemos que se intervino en el reloj:

"Se procedió a desarmar, bruñir, y volver a montar la maquinaria del reloj y las transmisiones de movimiento a la campana y a la esfera situada en el cuerpo de campanas. Se fabricó una rueda de engrane de bronce y dos pescantes con sus soportes correspondientes, se doró y pintó la caja y se colocó un cierre de hierro con cristales." (Jiménez 1986:124, citado en González-Varas 1994: 298).

Precisamente en este año de 1866, hemos identificado el presente expediente: Gobierno de la Provincia, arreglo de Relojes de la Catedraß ${ }^{\beta 1}$, interviene un agente colectivo socioeconómico de la 
administración provincial, una entidad externa a la Catedral en la conservación y restauración de estos instrumentos de medida ${ }^{32}$.

Tal y como hemos podido comprobar a través del estudio de las comisiones, los criterios e informes, obtenemos los nombres propios de las personas relacionadas con el devenir de la colección catedralicia, y entre ellos, los nombres de los conservadores y restauradores ${ }^{33}$. Del año 1875, José Rivero, restaurador $1^{\circ}$ del Museo Nacional de Pinturas, se ofrece de manera particular a restaurar el cuadro la Visión de San Antonio de Murillo, quien finalmente fue restaurado por Salvador Martínez Cubells. Unos años más tarde, en 1907, conocemos a José Escacena y Diéguez, restaurador de la Virgen de la Antigua de la Catedral, designado "Restaurador de los cuadros de la Catedral". Anterior a éste lo fue Manuel Lucena, también restaurador identificados ambos en la obra de Serrera (1987). Sin fecha concreta, obtenemos el nombre de Juan Oliva, restaurador, por su ofrecimiento de restaurar la Virgen de la Antigua que fue desestimado a favor de José Escacena.

\section{Conclusiones}

Como conclusión, podemos confirmar el papel y el significado de la Catedral como agente protector y difusor de las artes decimonónicas. Constituida como una institución museística en una red interinstitucional, la Catedral ha sido abanderada en la salvaguarda del patrimonio respecto a las instituciones culturales de su época. Se abre, por tanto, una nueva manera de investigar y sobre la que establecer un futuro método contrastado y válido en la elaboración de Planes de Catedrales, en los que se requiere analizar las sinergias pasadas para proyectar las futuras con éxito, en las que el género epistolar de Archivo se convierte así en una herramienta con una información dinámica de toda una declaración de intereses, pensamientos, decisiones, actuaciones en conservación y restauración tanto de la fábrica como de los bienes que custodia, y no sólo procedentes del órgano gestor principal, el Cabildo, sino que en este intercambio se genera una órbita de agentes externos, instituciones e individuos, que con sus actuaciones están reconociendo y posicionando a la Catedral de Sevilla no sólo como templo religioso sino como institución patrimonial.

\section{Notas}

[1] Procede de la Secretaría de Estado y consta de una carta dirigida al Deán Metropolitano Catedral de Sevilla con fecha del 19 de septiembre de 1827, y documentación Anexa que es la Real Cédula de 6 de julio de 1803. A.C.S. Fondo Capitular. Fondo Histórico General. Num. Leg. 11257. A, № Exp. 20.

[2] A.C.S. Fondo Capitular. Fondo Histórico General. Num. Leg. 11257. A, № Exp. 20

[3] A.C.S. Fondo Capitular. Secretaría. Correspondencia. Num. Leg. 11172, № Exp. 16

[4] A.C.S. Fondo Capitular. Fondo Histórico General. Num. Leg. 11338, № Exp. 5

[5] A.C.S. Fondo Capitular. Secretaría correspondencia. Num. Leg. 11191, № Exp. 10

[6] A.C.S. Fondo Capitular. Secretaria correspondencia, Num. Leg. 11173, № Exp. 6

[7] Viene a subrayar la génesis del perfil del conservador-restaurador en contraposición con el perfil del conservador-arquitecto del cual tenemos numerosas noticias y referencias documentales.

[8] A.C.S. Fondo Capitular. Fondo Histórico General, Num. Leg. 11338, № Exp. 11

[9] A través de la Real Orden de 13 de junio de 1844 se crean las Comisiones de Monumentos Históricos y Artísticos. La comisión de Monumentos de Sevilla se creó el 12 de septiembre de 1844, López, 2010:179. 
[10] A.C.S. Fondo Capitular. Secretaría. Correspondencia Num. Leg. 11172, № Exp. 18

[11] A.C.S. Fondo Capitular. Secretaría. Correspondencia. Num. Leg 11173. № Exp. 15

[12] A.C.S. Fondo Capitular. Secretaría. Correspondencia. Num. Leg 11175. № Exp. 14

[13] A.C.S. Fondo Capitular. Secretaría. Correspondencia. Num. Leg № 11176. Exp. 1

[14] Casanova elaboró una Memoria informativa con un primer reconocimiento de la Catedral previa a la intervención restauradora.

[15] A.C.S. Fondo Capitular. Fondo Histórico General, Num. Leg 11318. № Exp. 22

[16] A.C.S. Fondo Capitular. Secretaría. Correspondencia. Num. Leg 11172. № Exp. 18

[17] A.C.S. Fondo Capitular. Secretaría. Correspondencia. Num. Leg 11176. № Exp. 6

[18] A.C.S. Fondo Capitular. Secretaría. Correspondencia. Num. Leg 11176. № Exp. 5

[19] A.C.S. Fondo Capitular. Secretaría. Correspondencia. Num. Leg 11176. № Exp. 6

[20] A.C.S. Fondo Capitular. Secretaría. Correspondencia. Num. Leg 11176. № Exp. 6

[21] A.C.S. Fondo Capitular. Secretaría. Correspondencia. Num. Leg 11181, № Exp. 5

[22] A.C.S. Fondo Capitular. Secretaría. Correspondencia. Num. Leg 11176. № Exp. 6

[23] A.C.S. Fondo Capitular. Secretaría. Correspondencia. Num. Leg 11176. № Exp. 6

[24] A.C.S. Fondo Capitular. Secretaría. Correspondencia. Num. Leg 11290/3. Diversos

[25] A.C.S. Fondo Capitular. Fondo Histórico General. Num. Leg. 11338. № Exp. 11

[26] A.C.S. Fondo Capitular. Fondo Histórico, 11338, Exp. 11

[27] A.C.S. Secretaría. Correspondencia. 11170. Exp. 19

[28] A.C.S. Fondo Capitular. Secretaría. Correspondencia. Num. Leg 11174. № Exp. 7

[29] A.C.S. Fondo Capitular. Secretaría. Correspondencia. Num. Leg 11176. № Exp. 8

[30] A.C.S. Fondo Capitular. Secretaría. Correspondencia. Num. Leg 11177. № Exp. 8

[31] A.C.S. Fondo Capitular. Secretaría. Correspondencia. Num. Leg 11182. № Exp. 16

[32] Con toda probabilidad se trate del reloj de la Giralda, restaurado en 1866 y comentado anteriormente.

[33] Cabe señalar la contraposición entre los restauradores de pintura que procedían de la Academia, los arquitectos-restauradores de la fábrica catedralicia y finalmente, los restauradores de los bienes muebles, que son considerados como artesanos.

\section{Bibliografía}

CORTEGANA, J (1957). "Restauración del gran cuadro de Murillo: La Visión de San Antonio de Padua”, Archivo Hispalense № 81-82: 107-110.

BRAVO BERNAL, A.M. (2008). El Sagrario, un problema y su historia: estudio Arquitectónico y Documental de la Capilla del Sagrario de la Catedral de Sevilla. Sevilla: Universidad de Sevilla y Fundación Focus-Abengoa.

GALÁN, A. (2012). "El Patrimonio cultural. Una investigación sobre el patrimonio cultural y su gestión en los Archivos de la Catedral de Sevilla", en Actas del V Congreso Grupo Español del IIC Patrimonio cultural. Criterios de calidad en intervenciones. Madrid, GEIIC: 315-322.

GESTOSO Y PÉREZ, J. (1892). Historia y descripción de la Sacristía Mayor de la Catedral de Sevilla y de las preciosidades artísticas que en ella se custodian. Sevilla: Imprenta de la Revista de Tribunales. 
GESTOSO Y PÉREZ, J. (1889). Sevilla Monumental y Artística. Historia y descripción de todos los edificios notables, religiosos y civiles, que existen actualmente en esta ciudad y noticias de preciosidades artísticas y arqueológicas que en ellos se conservan, Sevilla.

GESTOSO Y PÉREZ, J. (1889). Catálogo de las obras que forman la Exposición retrospectiva de la pintura Sevillana. Celebrada en esta ciudad, en virtud del acuerdo de su Excmo. Ayto. durante el mes de abril del presente año de 1896. Sevilla: Tip. de la Región, San Eloy, nº 32.

GÓMEZ DE TERREROS GUARDIOLA,. M. del V. (2007). "La Catedral de Sevilla en 1880: Informe de los arquitectos Manuel Portillo y Juan Talavera sobre el estado del edificio", Laboratorio de Arte, 20: 363-372.

GONZÁLEZ-VARAS IBÁÑNEZ, I. (1994). La Catedral de Sevilla (1881-1900): El debate sobre la restauración monumental. Sevilla: Diputación de Sevilla.

LAGUNA PAUL, T. (2003). "Transformaciones en la Sacristía Mayor de la Catedral de Sevilla y otras reorganizaciones durante el siglo XIX", separata Catedrales Españolas, Murcia: Universidad de Murcia.

LUQUE CEBALLOS, I. (1996). "La Catedral de Sevilla: ¿Museo o Catedral?", Revista Atrio, № 8/9: 223-232.

RALLO GRUSS, C. (1995). "Memoria de la restauración del San Antonio de Murillo en el Archivo de la Academia de San Fernando", Atrio, no 7:77-93.

RUIZ DE LACANAL RUIZ-MATEOS, Ma D. (1999). El Conservador-Restaurador de Bienes Culturales. Historia de la profesión. Madrid: Síntesis.

SERRERA CONTRERAS, J. (1990). "La Virgen de la Antigua: Informes y restauraciones, Siglo XVIII-XIX", Archivo Hispalense, № 73, 223: 171-176.

SERRERA CONTRERAS, J.M. (1999). "Los ideales neoclásicos y la destrucción del Barroco. Ceán Bermúdez y Jerónimo Balbás", Archivo Hispalense n²23: 135-218.

VICENTE RABANAQUE, M. T. (2010). Historia de la Restauración. Del clásico estudio del objeto al sujeto como objeto de estudio, Tesis doctoral inédita. Facultad de Bellas Artes de la Universidad de Valencia.

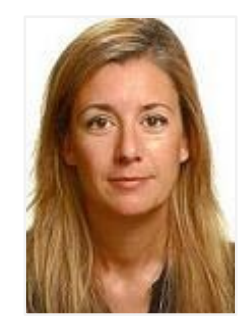

\section{Ana Galán Pérez}

am.gp.mail@gmail.com

Licenciada en Historia del Arte y Doctora en Bellas Artes. Es miembro activo del Grupo de Investigación HUM673 SOS Patrimonio, así como del GE-IIC y participa de la Junta Directiva de ACRE. Especializada en Conservación y Restauración de Bienes Culturales por la Escuela Superior de Barcelona (ESCRBCC) y postgraduada por la Facultad de Bellas Artes de Barcelona. Master en Gestión Cultural, Patrimonio y Museos, ha sido becada por el Museu Maritim de Barcelona y por el SCRBCC, el Servei de Conservacio y Restauracio de la Generalitat de Catalunya. Autora de estudios y artículos relacionados con la conservación y gestión patrimonial en la Historia, y nuevas metodologías de investigación en Archivos Históricos, con especial atención en la perspectiva social del patrimonio cultural.

Artículo recibido el 29/07/2012

Artículo aceptado el 14/04/2013 